\title{
The current knowledge of hyperaccumulator plants
}

\author{
Yao He ${ }^{1}$, Na Ding ${ }^{1}$, Mengxuan $\operatorname{Han}^{1}$, Xinshuai Wang ${ }^{1}$, Hua Lin ${ }^{1}$, Guo Yu${ }^{1 *}$ \\ ${ }^{1}$ Guangxi Key Laboratory of Environmental Pollution Control Theory and Technology, Guilin University of Technology, Guilin, China
}

\begin{abstract}
In recent years, heavy metal pollution in soil has become a serious problem. Remediation technologies have been developed, such as physical remediation, chemical remediation, microbial remediation and other technologies. Among them, phytoremediation has been widely used in practice. In this paper, the present situation of heavy metal pollution in soil in China, the research progress of remediation technology of heavy metal contaminated soil and the remediation of heavy metal contaminated soil by hyperaccumulators are reviewed, to help with follow-up research in this area.
\end{abstract}

\section{Introduction}

Heavy metals are closely related to human life and will have an impact on ecology during the mining process. As environmental problems continue to emerge, mankind has also begun to continuously explore ways to control pollution. Soil is the foundation of our survival and development. Nowadays, the problem of heavy metal pollution in soil is becoming increasingly prominent and has become a hot issue in today's society. Soil pollution is a process of gradual accumulation, with a certain degree of stagnation, concealment and destructiveness. Soil heavy metal pollution not only harms the growth of crops, but also causes migration, which can cause various diseases as the food chain enters the human body ${ }^{[1]}$. From the perspective of the remediation of soil contaminated by heavy metals in China, achieving high efficiency and low consumption is important. Among them, the superenriched plants have super-enrichment and supertolerance to heavy metals, which is an effective way to reduce soil pollution of heavy metals, protect human health, and realize green remediation. This paper describes the research progress, results and prospects of high accumulation soil remediation of heavy metal contaminated soil, and provides help for the remediation of heavy metal contaminated soil in China.

\section{Overview of soil heavy metal pollution in China}

When the content of heavy metals in the soil exceeds its purification limit, the heavy metal pollution in the soil in China is summarized ${ }^{[2]}$. According to statistics, the excess rate of mercury, nickel, zinc, lead, arsenic, copper and cadmium is $21.49 \%$, of which cadmium and lead are the main heavy metal pollutants ${ }^{[3]}$. The main ways of the pollution are agricultural activities, industrial pollution and human life.

According to the research, it is not the total concentration that determines the level of heavy metal pollution in soil, but the toxicity to plants, microorganism and humans ${ }^{[4]}$. The standard value of heavy metal content in soil is specified in relevant documents. Therefore, the prevention and control of soil heavy metals must be controlled from the source. The first is to strengthen the management of the soil; the second is to strictly control and eliminate the sources of pollution; the third is to actively restore the contaminated areas and rationally use soil remediation technologies to improve and enhance the quality of the soil.

\section{Heavy metal contaminated soil remediation technology}

\section{1 physical remediation technology}

Physical remediation technology refers to the use of physical methods of pollutants and soil separation or decontamination technology. Physical remediation technology including soil replacement method, soil exchange method, isolation method, thermal desorption, vitrification and electrical remediation technology. Among them, the foreign soil method and soil exchange method mainly cover the soil contaminated by heavy metals with surface cover, plow the soil deeply, or clean the contaminated soil and then backfill the uncontaminated soil. Isolation method refers to a method of dividing and isolating soil contaminated areas by using impermeable materials. Thermal desorption is the use of heat conduction or radiation to repair the soil, and separate pollutants from the soil through direct or indirect heating. The vitrification repair technology is to heat the contaminated soil to melt and then cool down to finally form a glassy substance. The electro-remediation technology is to insert the electrodes into heavily polluted soil, and collect heavy metal ions in the soil by adding current to form an electric field ${ }^{[5]}$. 


\section{2 chemical remediation}

Chemical remediation is a process in which chemicals are added to contaminated soil to degrade pollutants through chemical reactions between chemicals and pollutants. Chemical fixation technology is to reduce the mobility and solubility of pollutants by using the role of heavy metal adsorption, coprecipitation or ion exchange of curing agent. Chemical reduction technology uses strong reductive chemical reagents to reduce the valence of heavy metals in the soil, thus reducing the toxicity. The soil leaching method uses chemical leaching fluid to inteact with heavy metal pollutants, and finally separates the pollutants and the cleaning fluid from the soil together ${ }^{[6]}$.

\section{3 bioremediation}

Bioremediation technology mainly uses organisms with strong vitality and degradability to absorb, transform, and degrade heavy metal pollutants, and finally realize the role of soil environmental remediation. Bioremediation technologies mainly include phytoremediation technology, animal remediation technology, and microbial remediation technology. Phytoremediation uses natural or cultivated plants to absorb heavy metals. Animal remediation uses the life activities of lower animals to absorb heavy metals. Microbial remediation is the use of local, foreign or artificially cultivated functionalized microbes that can adapt to the polluted environment to reduce toxic pollutants through their own metabolism ${ }^{[7-9]}$.

\section{4 biochar remediation technology}

Biomass charcoal is a carbon material formed by pyrolyzing and carbonizing biomass such as trees, agricultural wastes, and animal tissues under anaerobic or partial hypoxia and relatively low temperature conditions ${ }^{[10]}$. Some scholars have studied and summarized the biochar remediation of heavy metal contaminated soil, clarified the preparation methods and characteristics of biochar, and discussed the application and principle of biochar in the remediation of heavy metal pollution of soil ${ }^{[11-12]}$.

\subsection{Joint prosthetics}

Physical remediation technology, chemical remediation technology, biological remediation technology and biochar remediation technology have their own advantages and disadvantages in remediation of heavy metal contaminated soil, and there are certain limitations in a single application. Therefore, we will use a variety of composite remediation technologies combined with their respective advantages to make the repair more effective. At present, some scholars have studied that the synergy between earthworms and biochar will increase soil biodiversity and improve soil quality; the fixation of heavy metals by earthworms and pig manure; chlorophytum and earthworms are effective in repairing soil contaminated by heavy metals ${ }^{[13]}$.

\section{The research progress of hyperaccumulators}

\section{1 definition of hyperaccumulators}

Hyperaccumulators are plants that can absorb 100 times more heavy metals than other plants. There are three characteristics as follows: most of heavy metals absorbed by plants are distributed in the aboveground part, which has a high ratio of aboveground to root; the concentration of some element in the body is higher than a certain critical value; the growth of plants does not show obvious signs of toxicity ${ }^{[14]}$.

\section{2 heavy metal phytoremediation}

When the soil is contaminated with heavy metals, the plants and small animals that live there will be affected first ${ }^{[15]}$. The accumulation of heavy metals in the soil will be toxic to plants, and plant roots will absorb the heavy metal ions in the soil and then transfer them. If the concentration of heavy metals in the soil is too high, it will affect soil fertility, agricultural yield and microbial activity. In order to avoid the occurrence of this kind of situation, the super-enriched plants are the basic application to purify polluted soil and industrial waste. In recent years, different types of hyperaccumulators have been found in China, including buckwheat ${ }^{[16]}$, sedum alfredii hance, leersia hexandra, pteris vittata and chrysanthemum ${ }^{[17]}$. Today these plants are roughly divided into ferns, herbaceous, crops, and woody plants. Pteridophyte hyperaccumulators generally have no economic value and cannot be eaten, and can only be used for landscape viewing. However, these plants have the characteristics of fast growth and large biomass. Therefore, these plants have a strong role in the accumulation of heavy metals. The economically valuable super-enriched herbaceous plants are mainly edible plants and crops. Woody plants have a long growth cycle and are generally larger in size. After it grows up, it has a certain ecological restoration function, which has a higher restoration effect on the ecological system of the area while repairing the contaminated soil.

\subsection{Study on the enrichment effect of hyperaccumulator on heavy metals in soil}

\subsection{1 mechanism of heavy metal accumulation by hyperaccumulators}

The super-enrichment of heavy metal elements by plants is a complex and rare natural phenomenon, which is the result of biological adaptation and evolution. The solubilization and aboveground accumulation of heavy metals by root exudates and microorganisms are the key mechanisms of the process of hyperaccumulation ${ }^{[18]}$.

Firstly, root exudates create an acidic environment in the rhizosphere, which promotes the dissolution of heavy metals in the soil ${ }^{[19]}$. Under the condition of heavy metal pollution, the roots of hyperaccumulators can secrete more 
soluble organic matter, which makes the $\mathrm{pH}$ value of the rhizosphere soil lower. Under such acidic conditions, the bioavailability of heavy metals is higher. At the same time, some specific root exudates can complex with heavy metals to form soluble complexes to promote enrichment. Root exudates and plant rhizosphere microorganisms Interaction to enhance the bioavailability of soil heavy metals $1^{[20-21]}$. Secondly, hyperaccumulator plants absorb heavy metals through plastid and apoplast pathways, and then transport them through xylem. In the symplast pathway, heavy metals enter the cell through the root cell membrane. In the apoplast pathway, they do not need to pass through the cell membrane and enter the root directly from the root tip and lateral root gap. After heavy metals enter the roots, they will be transported from the roots to the above-ground part through the xylem and phloem. Heavy metals can be transported up to seeds and new leaves through the phloem, and can also be transported down to root cells ${ }^{[22]}$. Thirdly, after the heavy metals accumulate in the roots, they are transported to the leaves and stems to achieve the enrichment and isolation of heavy metals through the vacuoles above the ground ${ }^{23}$. The heavy metals are mainly stored in the vacuoles of the leaves, so as to avoid damage to the important physiological processes of the cells ${ }^{[23-24]}$.

\subsubsection{Advances in research on phytoremediation of heavy metals in soil by hyperaccumulators}

\subsubsection{Plant-remediation material joint restoration}

Under the condition of $\mathrm{PCBs}+\mathrm{Cd}$ compound pollution, adding nano-zero-valent iron and loading nano-zerovalent iron can improve the ability of maidenhair to repair PCBs; under the condition of $\mathrm{PCBs}+\mathrm{Pb}$ compound pollution, vermiculite-loaded nano-zero-valent iron and activated carbon-loaded nano-zero-valent iron pair Impatiens has a certain promoting effect in repairing $\mathrm{PCBs}+\mathrm{Pb}$ composite contaminated soil, especially the effect of extracting and repairing $\mathrm{Pb}$. However, different modification methods of nano-zero-valent iron have different performance in the repairing effect. The addition of original nano-zero-valent iron can enrich $\mathrm{Pb}$. The set plays an inhibitory role ${ }^{[25]}$.

\subsubsection{2 plant-microbial remediation.}

There are certain heavy metal resistance genes in prokaryotes. Studies have found that the resistance genes of bacteria and cyanobacteria can also be transferred horizontally, and this combination will ultimately achieve the anti-metal effect. In practical applications, one method is to inoculate functional microorganisms into plants or soil, which can not only promote the growth of plants, but also improve the resistance of microorganisms to metals. Because endophytes are easily affected by the environment, so there are fewer application. The other is to add foreign matter on the basis of original and combined. There are also some problems with both methods. for example, some bacteria cannot resist in the actual contamination $^{[26]}$. Plant-microbe joint remediation technology is in-situ, highly efficient, and does not cause secondary pollution. It has shown broad application prospects in the treatment of heavy metal contaminated soil. However, the current research on plant-microbe joint remediation of heavy metal pollution in soil is still in the preliminary stage, and only certain progress has been made in laboratory research. Moreover, it is an extremely complex interaction process between plants, microorganisms, and soil. Its mechanism and influencing factors are still unclear, so it cannot be applied to largescale actual pollution of soil areas.

\subsubsection{Plant-plant joint restoration}

The results showed that plant interplanting could remediate heavy metal contaminated soil. Although it could affect the biomass of hyperaccumulators, the extraction rate and efficiency of heavy metals would be high $^{[27]}$. In this way, the migration performance of heavy metals will be correspondingly reduced, and the risk of heavy metal diffusion caused by water flow is also reduced, and secondary pollution is avoided. At present, the research in this area is not mature, there is still a lot of research space.

\section{Conclusion}

The treatment and remediation of heavy metal pollution in soils is one of the most important issues in the field of environmental science. Highly efficient and stable methods are being explored worldwide. Phytoremediation of hyperaccumulators are focused by domestic and foreign scholars. However, there are still some problems, such as the follow-up treatment of super-enriched plants, limited plant species, limited application, long cycle, heavy metal inhibitors to be developed, and food chain pollution problems. Therefore, while developing hyper-enriched phytoremediation technology, we must carefully consider its application risks and improve risk control measures.

Judging from the current research progress, the enrichment effect of super-enriched plants is closely related to the root system. We can study the effects of plant root exudates on the absorption of heavy metals by plants. In order to fully understand the accumulation mechanism of plants, we can study the dynamic process of plant root biomass. In addition, we can also use genomics to explore genes related to plant enrichment and tolerance, and reveal the law of action of hyper-enriched plants. In this way, more joint phytoremediation technologies can be developed to better repair soil contaminated by heavy metals.

\section{Acknowledgments}

The authors thank the financial supports from the Guilin Science and Technology Project (20190219-3)

\section{References}

1. Laquaz M, Dagot C, Bazin C, et al. Ecotoxicity and 
antibiotic resistance of a mixture of hospital and urban sewage in a wastewater treatment plant. J. Environ Sci Pollut Res Int, 25, 9243-9253 (2018)

2. Baker A J M. Accumulators and excluders-strategies in the response of plants to heavy metals. J. Journal of Plant Nutrition, 3, 643-654 (1981)

3. Krmer U. Metal hyperaccumulation in plants. J. Annual Review of Plant Biology, 61, 517-534 (2010)

4. $\mathrm{Xu} \mathrm{L} \mathrm{J,} \mathrm{zhang} \mathrm{M}$ L, Yang $\mathrm{H}$. Progress in bioremediation of soil heavy metal cadmium pollution. J. Journal of Nanjing normal university: Natural Science, 34, 102-106 (2011)

5. DalCorso G, Fasani E, Manara A, et al. Heavy Metal Pollutions: State of the Art and Innovation in Phytoremediation. J. Int J Mol Sci, 20, 3412 (2018)

6. Lianwen, Liu, Wei, et al. Remediation techniques for heavy metal-contaminated soils: Principles and applicability. J. Science of the Total Environment (2018)

7. Meuser H. Soil remediation and rehabilitation: treatment of contaminated and disturbed land. M. Springer Science \& Business Media (2012)

8. Pavel Coufalík, Pavel Krásensky, Dosbaba M, et al. Sequential extraction and thermal desorption of mercury from contaminated soil and tailings from Mongolia. J. Open Chemistry, 10, 1565-1573 (2012)

9. Zhang S, Ding Y, Lu X, et al. Rapid and efficient disposal of radioactive contaminated soil using microwave sintering method. J. Materials Letters, 175, 165-168 (2016)

10. Zeb A, Li S, Wu J, et al. Insights into the mechanisms underlying the remediation potential of earthworms in contaminated soil: A critical review of research progress and prospects. J. Science of the Total Environment (2020)

11. Wang Y, Luo Y, Zeng G, et al. Characteristics and in situ remediation effects of heavy metal immobilizing bacteria on cadmium and nickel co-contaminated soil. J. Ecotoxicology and Environmental Safety (2020)

12. Sanchez-Hernandez J C, Ro K S, Díaz F J. Biochar and earthworms working in tandem: Research opportunities for soil bioremediation. J. Science of the total environment, 688, 574-583 (2019)

13. Li F, Li Z, Mao P, et al. Heavy metal availability, bioaccessibility, and leachability in contaminated soil: effects of pig manure and earthworms. J. Environmental Science and Pollution Research (2018)

14. Brooks R R. Plants that hyperaccumulate heavy metals. J. CAB International, 1-2 (1989)

15. Baker A J M, Proctor J. The influence of cadmium, copper, lead and zinc on the distribution and evolution ofmetallophytes in the British Isles. J. Plant System Evolution, 173, 91-108 (1990)

16. Tamura H, Honda $\mathrm{M}$, Sato $\mathrm{T}$, Kamachi $\mathrm{H}$. $\mathrm{Pb}$ hyperaccumulation and tolerance in common buckwheat (Fagopyrum esculentum Moench). J. Plant Res, 118, 355-359 (2005)
17. Sheoran V, Sheoran A S, Poonia P. Phytomining: A review. J. Minerals Engineering, 22, 1007-1019 (2009)

18. Liu X, Fu J W, Guan D X, et al. Arsenic induced phytate exudation, and promoted $\mathrm{FeAsO} 4$ dissolution and plant growth in As-hyperaccumulator Pteris vittata. J. Environmental Science \& Technology, 50, 9070-9077 (2016)

19. Attwood T S, Unrine J M, Stone J W, et al. Uptake, distribution and toxicity of gold nanoparticles in tobacco (Nicotiana xanthi) seedlings. J. Nanotoxicology, 6, 353-360 (2012)

20. Solis D F A, Gonzalez C M C, Carrillo G R, et al. Accumulation and localization of cadmium in Echinochloa polystachya grown within a hydroponic system. J. Journal of Hazardous Materials, 141, 630636 (2007)

21. Chi K Y, Zou RWang L, et al. Cellular distribution of cadmium in two amaranth (Amaranthus mangostanus L.) cultivars differing in cadmium accumulation. J. Environmental Science and Pollution Research, 26, 22147-22158 (2019)

22. Mori S, Uraguchi S, Ishikawa S, et al. Xylem loading process is a critical factor in determining $\mathrm{Cd}$ accumulation in the shoots of Solanum melongena and Solanum torvum. J. Environmental and Experimental Botany, 67, 127-132 (2009)

23. Hu P J, Wang Y D, Przybylowicz W J, et al. Elemental distribution by cryo-micro-PIXE in the zinc and cadmium hyperaccumulator Sedum plumbizincicola grown naturally. J. Plant and Soil, 388, 267-282 (2015)

24. B G, J H J, D Y S, Uptake of metals by plants sharing a rhizosphere with the hyperaccumulator Thlaspi caerulescens. J. International Journal of Phytoremediation, 4, 267-281 (2002)

25. Jiang C A, Wu Q T, Sterckeman T, et al. Co-planting can phytoextract similar amounts of cadmium and zinc to mono - cropping from contaminated soils. J, Ecological Engineering, 36, 391-395 (2010)

26. Gaur A, Adholeya A. Prospects of arbuscular mycorrhizal fungi in phytoremediation of heavy metal contaminated soils. J. Current Science, 86, 528534 (2004)

27. Mani D, Kumar C. Biotechnological advances in bioremediation of heavy metals contaminated ecosystems: an overview with special reference to phytoremediation. J. International Journal of Environmental Science \& Technology, 11, 843-872 (2014) 